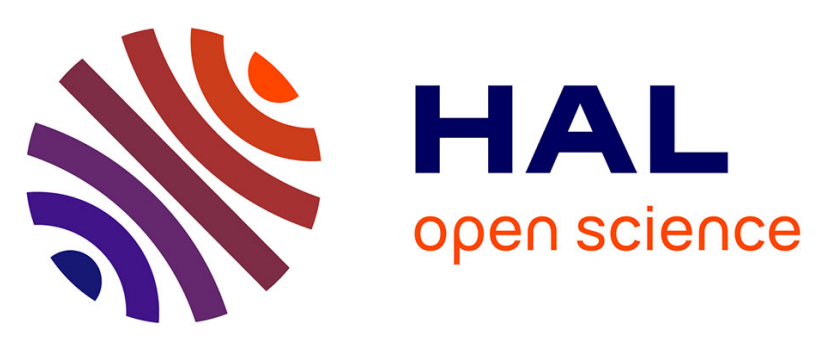

\title{
Near- infrared spectroscopy of palladium-containing layered double hydroxides used as catalysts
}

Manuel Mora, María I. Lopez, César Jiménez-Sanchidrián, José R. Ruiz

\section{To cite this version:}

Manuel Mora, María I. Lopez, César Jiménez-Sanchidrián, José R. Ruiz. Near- infrared spectroscopy of palladium-containing layered double hydroxides used as catalysts. Journal of Physics and Chemistry of Solids, 2011, 72 (3), pp.214. 10.1016/j.jpcs.2010.12.012 • hal-00720573

\section{HAL Id: hal-00720573 https://hal.science/hal-00720573}

Submitted on 25 Jul 2012

HAL is a multi-disciplinary open access archive for the deposit and dissemination of scientific research documents, whether they are published or not. The documents may come from teaching and research institutions in France or abroad, or from public or private research centers.
L'archive ouverte pluridisciplinaire HAL, est destinée au dépôt et à la diffusion de documents scientifiques de niveau recherche, publiés ou non, émanant des établissements d'enseignement et de recherche français ou étrangers, des laboratoires publics ou privés. 


\section{Author's Accepted Manuscript}

Near- infrared spectroscopy of palladium-containing layered double hydroxides used as catalysts

Manuel Mora, María I. Lopez, César Jiménez-Sanchidrián, José R. Ruiz

PII: S0022-3697(10)00446-4

DOI: doi:10.1016/j.jpcs.2010.12.012

Reference: PCS 6384

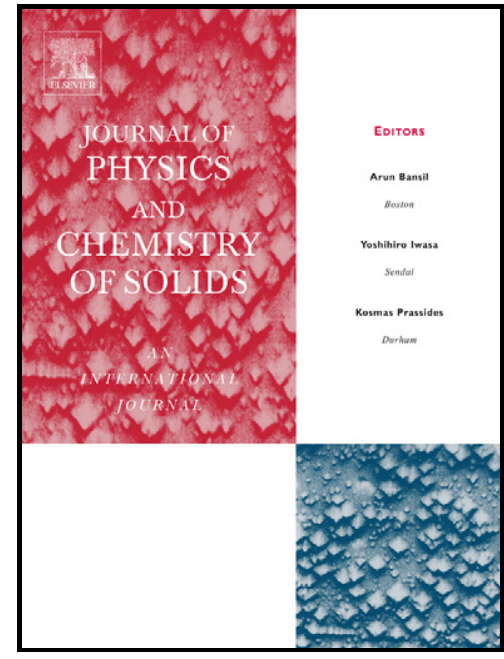

www.elsevier.com/locate/jpcs

To appear in: $\quad$ Journal of Physics and Chemistry of Solids

Received date: $\quad 18$ October 2010

Revised date: $\quad 14$ December 2010

Accepted date: 22 December 2010

Cite this article as: Manuel Mora, María I. Lopez, César Jiménez-Sanchidrián and José R. Ruiz, Near- infrared spectroscopy of palladium-containing layered double hydroxides used as catalysts, Journal of Physics and Chemistry of Solids, doi:10.1016/j.jpcs.2010.12.012

This is a PDF file of an unedited manuscript that has been accepted for publication. As a service to our customers we are providing this early version of the manuscript. The manuscript will undergo copyediting, typesetting, and review of the resulting galley proof before it is published in its final citable form. Please note that during the production process errors may be discovered which could affect the content, and all legal disclaimers that apply to the journal pertain. 


\section{Near- infrared spectroscopy of palladium-containing layered double hydroxides used as catalysts}

Manuel Mora, María I. Lopez, César Jiménez-Sanchidrián, José R. Ruiz,*

Departamento de Química Orgánica, Universidad de Córdoba, Campus de Rabanales, Edificio Marie Curie, Ctra Nacional IV-A, km 396, 14014 Córdoba, Spain

*Corresponding authors. E-mail: qo1ruarj@uco.es (Prof. J. R. Ruiz) 


\begin{abstract}
Three catalysts consisting of layered double hydroxides (LDHs) of magnesium and aluminium, and containing palladium in various forms, were synthesized and subsequently characterized by mid- and near-infrared spectroscopies. The results thus obtained are compared with those for a pure $\mathrm{Mg} / \mathrm{Al}$ layered double hydroxide. The spectra for the $\mathrm{Pd}$ containing LDHs (particularly the strength of the bands) were found to depend on the particular palladium form present. As a rule, the mid-infrared spectra contained a strong, broad band at $3800-2500 \mathrm{~cm}^{-1}$ due to stretching vibrations of the different types of hydroxyl groups present in the solids and another signal at ca. $1370 \mathrm{~cm}^{-1}$ due to the presence of carbonate ions in the interlayer region. These signals were the strongest in the near-infrared spectra, which were also quite similar, roughly, for all solids.
\end{abstract}

Keywords: LDH, Palladium catalysts, Mid-infrared spectroscopy, Near-infrared spectroscopy. 


\section{INTRODUCTION}

Structurally, layered double hydroxides (LDHs) consist of brucite-like layers where a fraction of $\mathrm{Mg}^{2+}$ ions in the formula, $\mathrm{Mg}(\mathrm{OH})_{2}$, have been isomorphically substituted by a trivalent cation (usually $\mathrm{Al}^{3+}$ ). The substitution causes an electron deficiency that is offset by anions occupying the interlayer region together with crystallization water [1]. The parent layered double hydroxide is the natural mineral hydrotalcite: $\mathrm{Mg}_{6} \mathrm{Al}_{2}(\mathrm{OH})_{16} \mathrm{CO}_{3} \cdot 4 \mathrm{H}_{2} \mathrm{O}$. Their easy synthesis and flexible composition has fostered the preparation of a variety of LDHs, the general formula for which is $\left.\mathrm{M}(\mathrm{II})_{1-\mathrm{x}} \mathrm{M}(\mathrm{III})_{\mathrm{x}}(\mathrm{OH})_{2}\right]^{\mathrm{x}+}\left[\mathrm{A}_{\mathrm{x} / \mathrm{n}}\right]^{\mathrm{n}-} \cdot \mathrm{mH}_{2} \mathrm{O}, \mathrm{M}(\mathrm{II})$ and $\mathrm{M}(\mathrm{III})$ denoting a divalent and a trivalent metal, respectively, and $\mathrm{A}$ an anion. A large number of LDHs containing diverse divalent and trivalent cations have been reported to date [2-4]. One of the divalent cations used to replace $\mathrm{Mg}^{2+}$ is $\mathrm{Pd}^{2+}$. Solids containing variable proportions of this metal have been successfully used in various organic synthesis processes [5-8].

Layered double hydroxides can also be used to obtain catalysts containing palladium in various forms ranging from chelates to neutral species anchored or supported on the solid surface to negatively charged complexes occupying the interlayer region and offsetting the initial charge deficiency $[11,12]$. These catalysts have also been used, with variable success, in organic synthesis [9-12], and characterized by using a number of diffraction and spectroscopic techniques. However, Pd-containing LDHs have never to date been examined by near-infrared spectroscopy (NIRS). This technique essentially provides information about bonds involving a hydrogen atom (especially, $\mathrm{O}-\mathrm{H}$ bonds). We therefore believed it of interest to use NIRS for the characterization of LDHs. In fact, NIR spectroscopy was previously used to examine various layered $\mathrm{Mg}(\mathrm{II}) / \mathrm{M}(\mathrm{III})$ double hydroxides with $\mathrm{M}(\mathrm{III})=$ $\mathrm{Al}, \mathrm{Ga}$ or In, as well as $\mathrm{Ni} / \mathrm{Al}, \mathrm{Ni} / \mathrm{Fe}$ and $\mathrm{Mg} / \mathrm{Fe}[14,15]$ or $\mathrm{Co} / \mathrm{Al}[16] \mathrm{LDHs}$. 
The aim of this work was to use the NIRS technique to characterize three $\mathrm{Mg} / \mathrm{Al}$ LDHs containing palladium in various forms. The solids had previously been used in the Suzuki cross-coupling reaction to obtain biphenyls [7]. Their results were compared with those for an $\mathrm{Mg} / \mathrm{Al} \mathrm{LDH}$ used as support for two of the catalysts. In addition, the solids were studied by mid-infrared spectroscopy in order to facilitate the unambiguous assignation of the NIR bands.

\section{EXPERIMENTAL}

\subsection{Catalysts synthesis}

The procedure used to synthesize the four Pd-containing $\mathrm{Mg} / \mathrm{Al} \mathrm{LDHs}$ studied is described elsewhere [17]. Briefly, the solids were prepared as follows: HT, which was used as support for the other three solids, was obtained by coprecipitation [18]; HT-Pd was prepared similarly to $\mathrm{HT}$, but using $0.5 \% \mathrm{Pd}$ to incorporate $\mathrm{Pd}^{2+}$ ions into the crystal network of the brucite-like layers [17]; $\mathrm{HT}-\mathrm{PdCl}_{4}$ was obtained by replacing the carbonate

ions in $\mathrm{HT}$ with $\mathrm{PdCl}_{4}{ }^{2-}$ [17]; finally, $\mathrm{HT}-\mathrm{PdAc}_{2} \mathrm{Py}_{2}$ consisted of a $\mathrm{Pd}(\mathrm{II})$ acetate-pyridine chelate anchored on the surface of solid HT. The target solids were therefore three catalysts containing palladium in various forms and the starting $\mathrm{Mg} / \mathrm{Al} \mathrm{LDH}$.

\subsection{Catalyst characterization}

As stated above, the studied solids were characterized for structure and surface properties by using various instrumental techniques as described elsewhere $[10,16]$. By way of summary, Table 1 gives the formula of each solid and its palladium content as determined by ICP-MS. The table also gives the lattice parameters for the solids as calculated from the 
XRD patterns of Fig. 1. Fourier transform infrared (FT-IR) and magic angle spinning nuclear magnetic resonance (MAS-NMR) spectroscopies had previously been used to characterize this type of catalyst, albeit as regards the interlayer ion only. In this work, we conducted a deeper FT-IR study of the solids that was completed by NIRS.

FT-IR (MIR) spectroscopy. The Fourier transform infrared spectra for the catalysts were recorded over the wavenumber range $4000-400 \mathrm{~cm}^{-1}$, using a spectral resolution of $4 \mathrm{~cm}^{-1}$ on a Perkin-Elmer Spectrum 100 FT-IR spectrophotometer. Samples were prepared by mixing the powdered solids with $\mathrm{KBr}$ (the blank) in a 18:85 ratio.

NIR spectroscopy. Near-infrared spectra were recorded on a Foss NIRSystems 6500 spectrometer. Individual spectra were obtained by co-adding 64 scans performed at a spectral resolution of $8 \mathrm{~cm}-1$ over the range $11000-4000 \mathrm{~cm}^{-1}$, using the DRIFT technique.

All spectral treatments applied (viz. baseline correction, smoothing, normalization and deconvolution) were done with the Peakfit v. 4.11 software package.

\section{RESULTS AND DISCUSSION}

\subsection{Characterization of catalysts}

Before discussing the MIR and NIR results obtained in this work, we believe it of interest to briefly comment on others reported in previous papers $[10,17]$. Table 1 shows the elemental composition of each solid. As can be seen, HT possessed a metal ratio identical with the theoretical value, which suggests that the cations were virtually completely incorporated into the solid phase. The amount of crystallization water present was estimated 
from thermogravimetric data. That of palladium was equal or close to $0.5 \%$ by weight -by exception, the water content of the catalyst containing $\mathrm{PdCl}_{4}{ }^{2-}$ ions was slightly higher than 10\%. Figure 1 shows the XRD patterns for the catalysts. The pattern for HT (Fig. 1a) is typical of an LDH [18], and so are those for the other three solids, which only differ in signal strength and width (a result of the differences in crystallinity introduced by the synthetic procedures used). The lattice parameters shown in Table 1 are consistent with the reported values for $\mathrm{LDHs}$ consisting of $\mathrm{Mg}$ and $\mathrm{Al}$ in a ratio close to 2 [4].

Accurately assigning the signals in the NIR region, which contains overtones and combination bands for stretching and/or deformation vibrations, required the prior identification of the bands in the MIR region, which led us to examine the MIR spectra for the catalysts first.

\subsubsection{MIR spectroscopy}

The MIR spectrum for an LDH can usually be split into three distinct zones for easier study. The first zone, which essentially contains the bands for the fundamental stretching vibrations of hydroxyl groups, spans the wavenumber range $4000-2500 \mathrm{~cm}^{-1}$ and is usually that exhibiting the strongest bands for the LDH. The second, from 1800 to $1200 \mathrm{~cm}^{-1}$, contains the signals for stretching vibrations of carbon-oxygen bonds in carbonate ions in the interlayer region in addition to deformation vibrations of water molecules. The third, which spans the range $1200-400 \mathrm{~cm}^{-1}$, contains the bands for deformation vibrations in carbonate and stretching vibrations in metal-oxygen bonds. A discussion of the bands observed in each zone follows.

Región MIR 4000-2500 $\mathrm{cm}^{-1}$ : Figure 2 shows the MIR spectra for the three catalysts and the $\mathrm{Mg} / \mathrm{Al} \mathrm{LDH}$ in this zone. As can be seen, all solids exhibited four signals the exact wavenumbers for which are given in Table 2. The two signals observed at the greater wavenumbers can be assigned to stretching vibrations of hydroxyl groups directly bonded to 
$\mathrm{Al}$ and $\mathrm{Mg}$ ions in octahedral brucite-like layers of the LDHs. The catalyst containing interlayer $\mathrm{Pd}^{2+}$ ions failed to give a third signal corresponding to $\mathrm{Pd}-\mathrm{OH}$ groups owing to the low proportion of metal used $(0.5 \%)$. The third component, observed at ca. $3100 \mathrm{~cm}^{-1}$, can be assigned to hydroxyl groups in water molecules forming hydrogen bonds with interlayer carbonate ions [19]. This signal was also present, but ill-defined, in the spectrum for solid $\mathrm{HT}-\mathrm{PdCl}_{4}$, which should in theory have contained no carbonate but, as shown by its elemental composition, contained some - much less than the other LDHs, which obviously led to a highly attenuated signal in its FT-IR spectrum.

Region MIR 1800-1200 $\mathrm{cm}^{-1}$ : This spectral window (Fig. 3) typically contains the bands for fundamental stretching vibrations of carbonate (mode $v_{3}$ ). Obviously, the spectrum for solid HT-PdCl $\mathrm{P}_{4}$ exhibited a much weaker signal than the others owing to its reduced carbonate content. Table 2 shows the exact wavenumbers for the normalized, deconvoluted bands. The presence of a shoulder above the signal for carbonate can be ascribed to a decreased symmetry in the ion activating vibrational mode $v_{1}$, which is inactive in symmetric carbonate molecules [20]. This second spectral zone also contained a well-defined band above $1600 \mathrm{~cm}^{-1}$ due to deformation vibrations of hydroxyl bonds in the water molecules [21].

Region MIR 1200-400 $\mathrm{cm}^{-1}$ : Carbonate ions in the interlayer region of an LDH possess planar symmetry typical of $\mathrm{D}_{3 \mathrm{~h}}$ groups [22] and are spectroscopically identical to free carbonate ions, which exhibit three active modes in the IR region. The first such mode, $v_{3}$, is described above and appears at ca. $1360 \mathrm{~cm}^{-1}$. The second appears at ca. $860 \mathrm{~cm}^{-1}$ and can be assigned to out-of-plane deformation vibrations $\left(v_{4}\right)$. Finally, the third active mode $\left(v_{2}\right)$ also corresponds to in-plane deformation vibrations but appears at ca. $675 \mathrm{~cm}^{-1}$. Table 2 shows the exact wavenumbers for each normalized, deconvoluted band obtained from the spectra of Fig. 4. The spectra additionally contained bands which can be assigned to translational modes of hydroxyl groups under the influence of trivalent aluminium atoms (signals at 780 and $550 \mathrm{~cm}^{-1}$ ), together with the respective deformation modes at 1030 and 
$950 \mathrm{~cm}^{-1}$. Finally, the band at the smallest wavenumber $\left(450 \mathrm{~cm}^{-1}\right)$ can be assigned to backbone vibrations of oxygen-bonded octahedral aluminium atoms (Al-O).

\subsubsection{NIR spectroscopy}

As previously done with the FT-IR spectra, the NIR spectra for the catalysts were also split into three different zones for easier study, namely: 11000-9000, 8000-6000 and 5500$4000 \mathrm{~cm}^{-1}$.

Región 11000-9000 $\mathrm{cm}^{-1}$ : This spectral zone contained a strong band that was deconvoluted into the signals shown in Fig. 5, the exact wavenumbers for which are given in Table 3. The zone exhibited the bands corresponding to the second overtone of stretching vibrations of the different types of $\mathrm{O}-\mathrm{H}$ bonds present in the solids. A solid containing a transition metal such as palladium can additionally give electronic bands, as previously reported for $\mathrm{Ni}$ and Co [16], and Fe [23]. The spectrum for the solid containing no palladium, HT, was that exhibiting the greatest number of signals and deconvoluted into four bands. The two bands at the greater wavenumbers (10452 and $10373 \mathrm{~cm}^{-1}$ ) can be assigned to the second overtone of stretching vibrations of $\mathrm{O}-\mathrm{H}$ bonds in the hydroxyl groups forming the brucite-like octahedral layers, which appeared at 3598 and $3499 \mathrm{~cm}^{-1}$ in the MIR spectrum. The third signal in the spectrum, observed at $10150 \mathrm{~cm}^{-1}$, corresponds to the second overtone of stretching vibrations of $\mathrm{OH}$ groups in water (the band at $3340 \mathrm{~cm}^{-1}$ in the MIR spectrum). Finally, the fourth band $\left(9692 \mathrm{~cm}^{-1}\right)$ can be assigned to the second overtone of stretching vibrations of $\mathrm{O}-\mathrm{H}$ bonds in water molecules bonded to carbonate ions in the interlayer region. As can be seen, none of the wavenumbers for the NIR spectra coincided exactly with three times the values for the MIR signals owing to the anharmonic nature of the vibrations. The catalysts containing palladium also gave the previous four signals, which differed in strength and were due to their octahedral layer structure. However, they additionally exhibited a signal at a greater wavenumber that can be assigned to electronic transitions between $d$ orbitals in the palladium atoms. This was the sole difference in this spectral region other than signal strength between the Pd-containing catalysts and the pure LDH. 
Also, the presence of the metal outside the octahedral layers resulted in substantially stronger signals.

Región 8000-6000 $\mathrm{cm}^{-1}$ : This zone contained four signals essentially due to the first overtone of stretching vibrations of $\mathrm{O}-\mathrm{H}$ bonds; hence, they were the strongest signals in the NIR spectrum (Fig. 6). The signals were somewhat weaker for the catalyst containing platinum in complexed form, whether intercalated $\left(\mathrm{HT}-\mathrm{PdCl}_{4}\right)$ or supported $\left(\mathrm{HT}-\mathrm{PdAc} \mathrm{Py}_{2}\right)$. Irrespective of signal intensity, all spectra contained an asymmetric component centred at ca. $7000 \mathrm{~cm}^{-1}$ that was deconvoluted into three bands. Similarly to the previous zone, these three signals can be assigned to the first overtone of vibrations of the different types of $\mathrm{O}-\mathrm{H}$ bonds present in the solids (see Table 3). Also, some solids exhibited a fourth, very weak band above $7500 \mathrm{~cm}^{-1}$ due to the addition or subtraction of the deformation mode for the split first overtone of the fundamental stretching vibration of the $\mathrm{OH}$ group (i.e. $2 v_{1}+\delta v$ ).

Región 5500-4000 $\mathrm{cm}^{-1}$ : This spectral zone contained two strong signals centred at ca. 5200 and $4400 \mathrm{~cm}^{-1}$ that were deconvoluted into several bands as shown in Fig. 7. The signal at the smaller wavenumber, which was deconvoluted into two bands, was a combination of several bands in the MIR region and is difficult to assign unambiguously. On the other hand, the bands at the greater wavenumber can be assigned to overtones of $\mathrm{O}-\mathrm{H}$ bonds in water and to carbonate combination bands that result from splitting of the symmetric and antisymmetric stretching vibrations for the anion $\left[2\left(v_{1}+v_{3}\right)\right]$.

\section{CONCLUSIONS}

Mid- and near-infrared spectroscopies were used here to characterize palladiumcontaining $\mathrm{Mg} / \mathrm{Al}$ layered double hydroxides (LDHs). The palladium was either inserted into the brucite-like layers of the $\mathrm{LDH}$, intercalated as $\mathrm{PdCl}_{4}{ }^{2-}$ in the interlayer region of the solid or supported as $\mathrm{PdAc}_{2} \mathrm{Py}_{2}$ on its surface. The catalysts, which were synthesized in previous work, exhibited a layered structure containing carbonate ions in the interlayer 
region; by exception, the presence of $\mathrm{PdCl}_{4}{ }^{2-}$ in one of the solids dramatically reduced the amount of intercalated carbonate. The MIR spectra for the solids exhibited three distinct zones exhibiting marked differences in fundamental stretching vibrations of hydroxyl groups present in the catalysts $\left(3800-2500 \mathrm{~cm}^{-1}\right.$ zone); such differences testify to the reduction in the amount of carbonate present in the catalyst containing palladium as an anionic chelate. This is also apparent from the decreased strength of the band for the stretching vibration of $\mathrm{C}-\mathrm{O}$ bonds, which appears at ca. $1370 \mathrm{~cm}^{-1}$. The NIR region allowed the pure $\mathrm{LDH}$ to be discriminated from the Pd-containing catalysts on the basis of the presence of electronic bands due to the metal, which appeared at ca. $10700 \mathrm{~cm}^{-1}$ (especially in the catalyst containing Pd as a chelate). Finally, the bands in the remainder of the NIR region exhibited significant differences in strength between catalyst types. 


\section{ACKNOWLEDGEMENTS}

The authors gratefully acknowledge funding by Spain's Ministerio de Ciencia e Innovación (Project MAT-2010-18778), Fondos Feder and to the Consejería de Educación y Ciencia de la Junta de Andalucía. 


\section{References}

[1] V. Rives, Layered Double Hydroxides: Present and Future. Nova Science Publishers, New York (2001).

[2] G. C. C. Arizaga, K. G. Satyanarayana, F. Wypych, Solid State Ionics 178 (2007) 1143-1162.

[3] C. Forano, T. Hibino, F. Leroux, C. Tabiot-Gueho. Handbook of Clay Science, Developments in Clay Science, Vol. I. Elsevier, Amsterdam (2006).

[4] F. Cavani, F. Trifiro, A. Vaccari, Catal. Today 11 (1991) 173-301.

[5] D. Tichit, M. J. Martinez Ortiz, D. Francova, C. Gerardin, B. Coq, R. Durand, F. Prinetto, G. Ghitti, Appl. Catal. A: General 318 (2007) 170-177.

[6] N. N. Das, S. C. Srivastava, Bull. Mater. Sci. 25 (2002) 283-289.

[7] F. Basile, G. Fornasari, M. Gazzano, A. Vaccari, Appl. Clay Sci. 18 (2001) 51-57.

[8] F. Basile, G. Fornasari, M. Bazzano, A. Vaccari, Appl. Clay Sci. 16 (2000) 185200.

[9] T. Nishimura, S. Uemura, Synlett. (2004) 201-216.

[10] C. Jiménez-Sanchidrián, M. Mora, J. R. Ruiz, Catal. Commun. 7 (2006) 10251028.

[11] J. Carpentier, J. F. Lamonier, S. Siffert, E. A. Zhilinskaya, A. Aboukais, Appl. Catal. A: General 234 (2002) 92-101.

[12] M. Lakshmi Kantam, P. Srinivas, K. B. Shiva Kumar, R. Trivedi, Catal. Commun. 8 (2007) 991-996.

[13] M. Mora, M. I. López, C. Jiménez-Sanchidrián, J. R. Ruiz, J. Sol-Gel Sci. Technol. (2010), in press.

[14] R. L. Frost, M. L. Weier, M. E. Clissold, P. A. Williams, Spectrochim. Acta A, 59 (2003) 3313-3319.

[15] R. L. Frost, H. J. Spratt, S. J. Palmer, Spectrochim. Acta 72 (2009) 984-988.

[16] Q. Tao, B. J. Reddy, H. He, R. L. Frost, P. Yuan, J. Xhu, Mater. Chem. Phys. 112 (2008) 869-875. 
[17] M. Mora, C. Jiménez-Sanchidrian, J. R. Ruiz, J. Coll. Interf. Sci. 302 (2006) 568575.

[18] M. A. Aramendía, Y. Avilés, J. A. Benítez, V. Borau, C. Jiménez, J. M. Luque, J. M. Marinas, J. R. Ruiz, F. J. Urbano, Microp. Mesop. Mater. 29 (1999) 319-328.

[19] W. Kagunya, R. Baddour-Hadjean, F. Kooli, W. Jones, Chem. Phys. 236 (1998) 225-234.

[20] M. J. Hernández-Moreno, M. A. Ulibarri, J. L. Rendón, C. J. Serna, Phys. Chem. Miner. 12 (1985) 34-41.

[21] M. A. Aramendía, Y. Avilés, V. Borau, J. M. Luque, J. M. Marinas, J. R. Ruiz, F. J. Urbano, J. Mater. Chem. 9 (1999) 1603-1607.

[22] O. Clause, M. Gazzano, F. Trifiro, A. Vaccari, L. Zatorski, Appl. Catal. 73 (1991) 217-224.

[23] R. L. Frost, B. J. Reddy, S. Bahfenne, J. Graham, Spectrochim. Acta A 72 (2009) 597-604. 
Table 1. Experimentally determined chemical composition and lattice parameters of the catalysts (from reference 17).

\begin{tabular}{ccccc}
\hline Catalyst & Formulae $^{\mathrm{a}}$ & $\% \mathrm{Pd}^{\mathrm{b}}$ & $a(\mathrm{~A})^{\mathrm{c}}$ & $c(\mathrm{~A})^{\mathrm{c}}$ \\
\hline $\mathrm{HT}$ & $\mathrm{Mg}_{0.670} \mathrm{Al}_{0.330}(\mathrm{OH})_{2}\left(\mathrm{CO}_{3}\right)_{0.165} \cdot 0.68 \mathrm{H}_{2} \mathrm{O}$ & - & 3.042 & 22.701 \\
$\mathrm{HT}-\mathrm{Pd}$ & $\mathrm{Mg}_{0.630} \mathrm{Pd}_{0.040} \mathrm{Al}_{0.330}(\mathrm{OH})_{2}\left(\mathrm{CO}_{3}\right)_{0.165} \cdot 0.54 \mathrm{H}_{2} \mathrm{O}$ & 0.5 & 3.030 & 22.173 \\
$\mathrm{HT}-\mathrm{PdCl}$ & $\mathrm{Mg}_{0.670} \mathrm{Al}_{0.330}(\mathrm{OH})_{2}\left(\mathrm{CO}_{3}\right)_{0.072}\left(\mathrm{PdCl}_{4}\right)_{0.094} \cdot 0.68 \mathrm{H}_{2} \mathrm{O}$ & 10.25 & 3.050 & 23.589 \\
$\mathrm{HT}^{\mathrm{PdAc}}{ }_{2} \mathrm{Py}$ & $\mathrm{Mg}_{0.670} \mathrm{Al}_{0.330}(\mathrm{OH})_{2}\left(\mathrm{CO}_{3}\right)_{0.165} \cdot 0.72 \mathrm{H}_{2} \mathrm{O}$ & 0.6 & 3.040 & 22.548 \\
\hline${ }^{\mathrm{a}}$ Chemical formula of the LDHs. & ${ }^{\mathrm{b}}$ Percent weight of palladium. ${ }^{\mathrm{c}}$ Lattice parameters. & &
\end{tabular}


Table 2. Infrared spectral analysis of synthetized catalysts (in $\mathrm{cm}^{-1}$ ).

\begin{tabular}{|c|c|c|c|c|}
\hline HT & HT-Pd & $\mathrm{HT}-\mathrm{PdCl}_{4}$ & $\mathrm{HT}-\mathrm{PdAc} \mathbf{P}_{2} \mathrm{Py}_{2}$ & Assignation \\
\hline 3598 & 3571 & 3584 & 3601 & MO-H stretching \\
\hline 3499 & 3449 & 3464 & 3460 & MO-H stretching \\
\hline 3340 & 3316 & 3323 & 3324 & Water $\mathrm{O}-\mathrm{H}$ stretching \\
\hline 3095 & 3071 & 3121 & 3070 & Water $\mathrm{O}-\mathrm{H}$ stretching bonding to carbonate \\
\hline 1615 & 1638 & 1630 & 1579 & Water $\mathrm{O}-\mathrm{H}$ bending \\
\hline 1406 & 1435 & 1451 & 1410 & $\mathrm{CO}_{3}$ stretching (reduced symmetry) \\
\hline 1363 & 1366 & 1372 & 1360 & $\mathrm{CO}_{3}$ antisymmetric stretching $\left(\operatorname{mode} v_{3}\right)$ \\
\hline 1032 & 1030 & 1016 & 1022 & Al-OH deformation \\
\hline 951 & 946 & 934 & 948 & Al-OH deformation \\
\hline 856 & 862 & 833 & 852 & $O_{3}$ bending out-of-plane (mode $v_{4}$ ) \\
\hline 782 & 784 & 739 & 779 & Al-OH traslation \\
\hline 676 & 675 & 648 & 677 & $\mathrm{CO}_{3}$ bending in-plane (mode $v_{2}$ ) \\
\hline 550 & 555 & 559 & 554 & Al-OH traslation \\
\hline 450 & 453 & 448 & 452 & Al-O skeleton \\
\hline
\end{tabular}


Table 3. Near infrared spectral analysis of synthetized catalysts $\left(\right.$ in $\left.\mathrm{cm}^{-1}\right)$.

\begin{tabular}{ccccc}
\hline HT & HT-Pd & HT-PdCl $_{4}$ & HT-PdAc $_{2} \mathbf{P y}_{2}$ & Assignation \\
\hline & 10777 & 10763 & 10727 & Electronic bands \\
10542 & 10578 & 10476 & 10557 & $2^{\text {nd }}$ overtone of M-OH stretching \\
10373 & 10341 & 10301 & 10273 & $2^{\text {nd }}$ overtone of M-OH stretching \\
10150 & 10146 & 10094 & 9997 & $2^{\text {nd }}$ overtone of water O-H stretching \\
9692 & 9629 & 9751 & 9657 & $2^{\text {nd }}$ overtone of water stretching bonding to $\mathrm{CO}_{3}$ \\
7855 & & & 7540 & $2 v_{1}+\delta v$ \\
7146 & 6997 & 7076 & 7035 & $1^{\text {st }}$ overtone of M-OH stretching \\
6991 & 6859 & 6917 & 6880 & $1^{\text {st }}$ overtone of M-OH stretching \\
6709 & 6576 & 6612 & 6590 & $1^{\text {st }}$ overtone of water O-H stretching \\
\hline
\end{tabular}


Figure 1. XRD patterns for the catalysts.

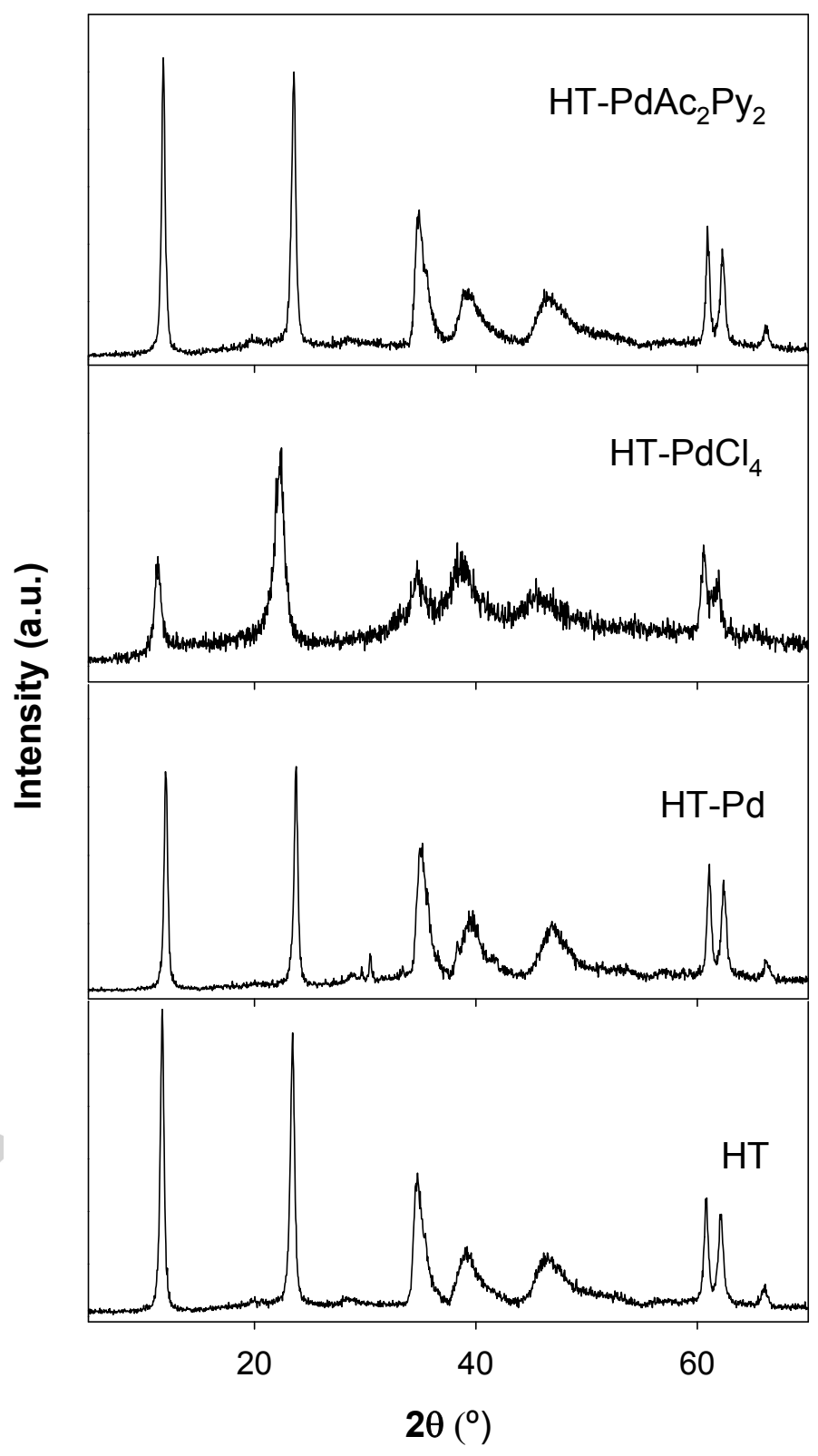


Figure 2. $4000-2500 \mathrm{~cm}^{-1}$ spectral region for the catalysts studied.

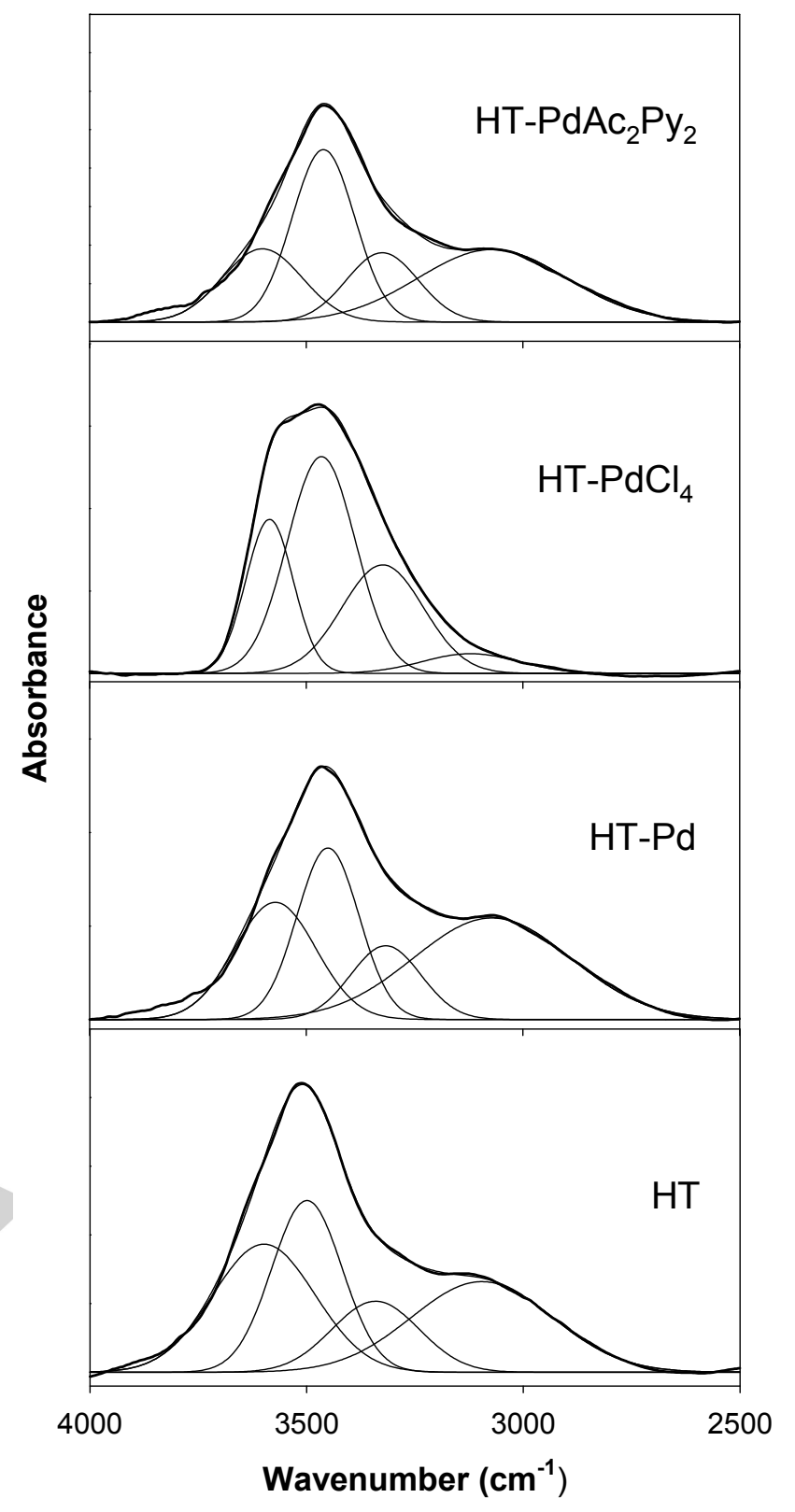


Figure 3. $1800-1200 \mathrm{~cm}^{-1}$ spectral region for the catalysts studied.

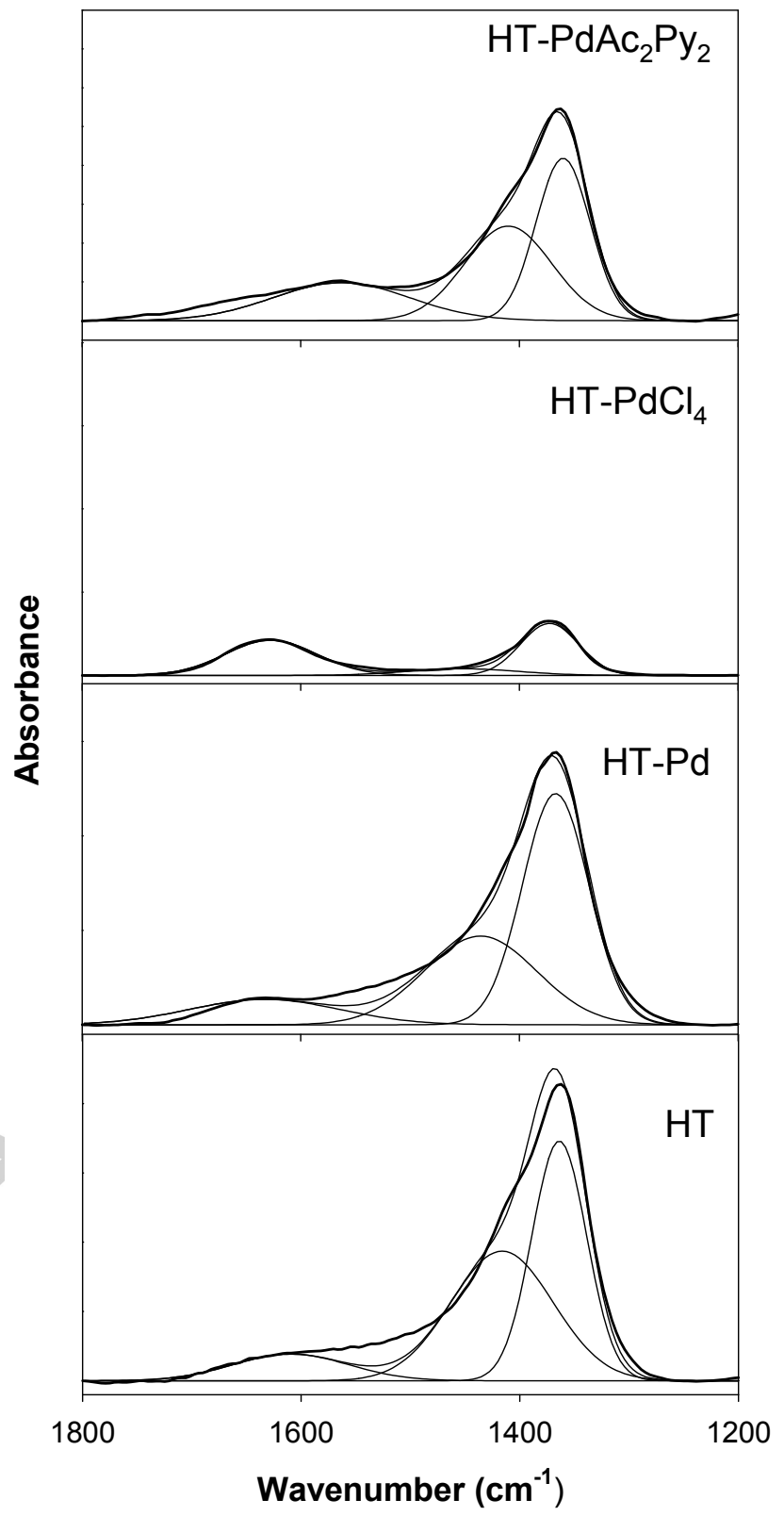


Figure 4. $1200-400 \mathrm{~cm}^{-1}$ spectral region for the catalysts studied.

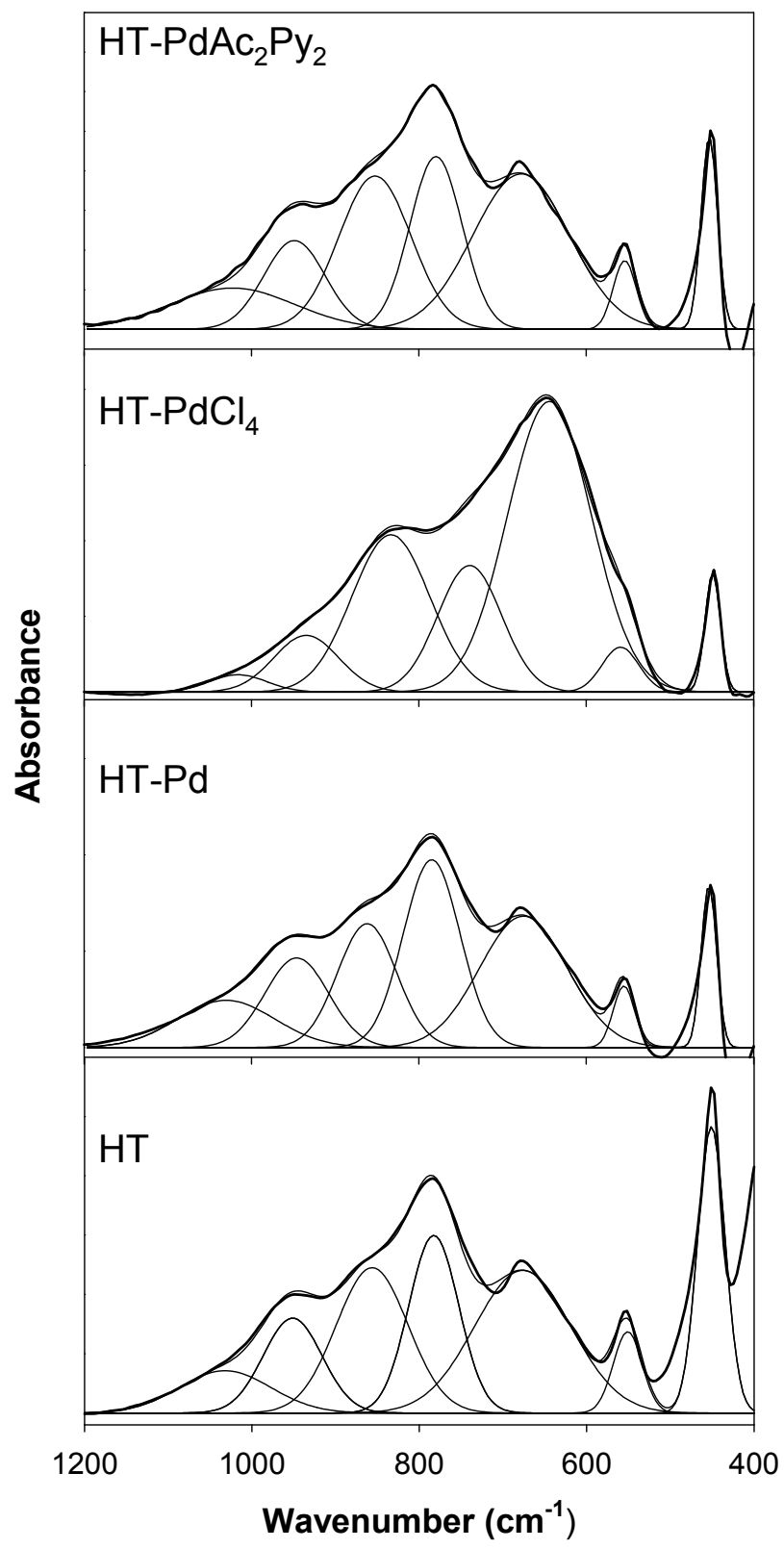


Figure 5. NIR spectra of synthesized catalysts in the $11000-9000 \mathrm{~cm}^{-1}$ region.

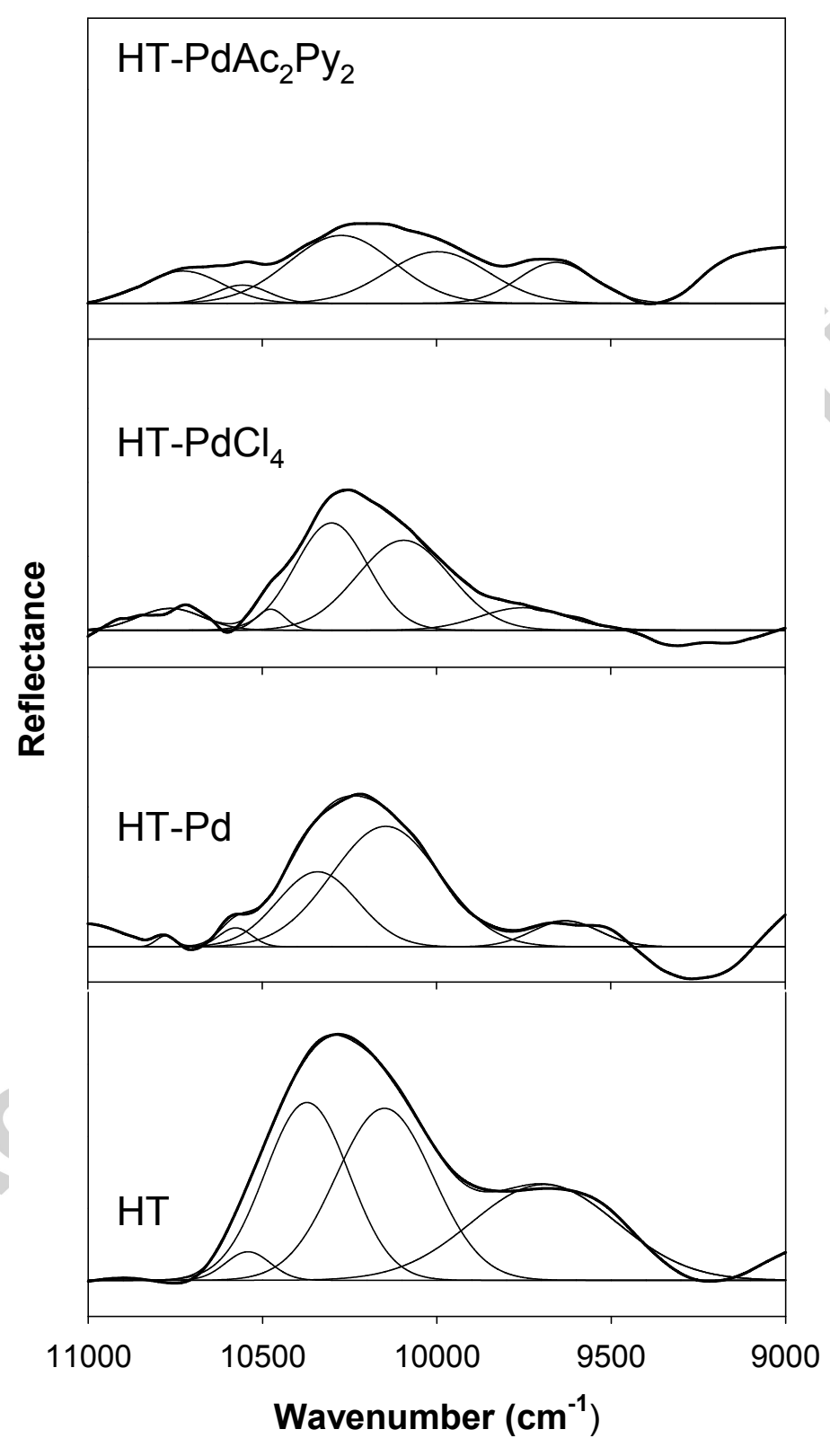


Figure 6. NIR spectra of synthesized catalysts in the $8000-6000 \mathrm{~cm}^{-1}$ region.

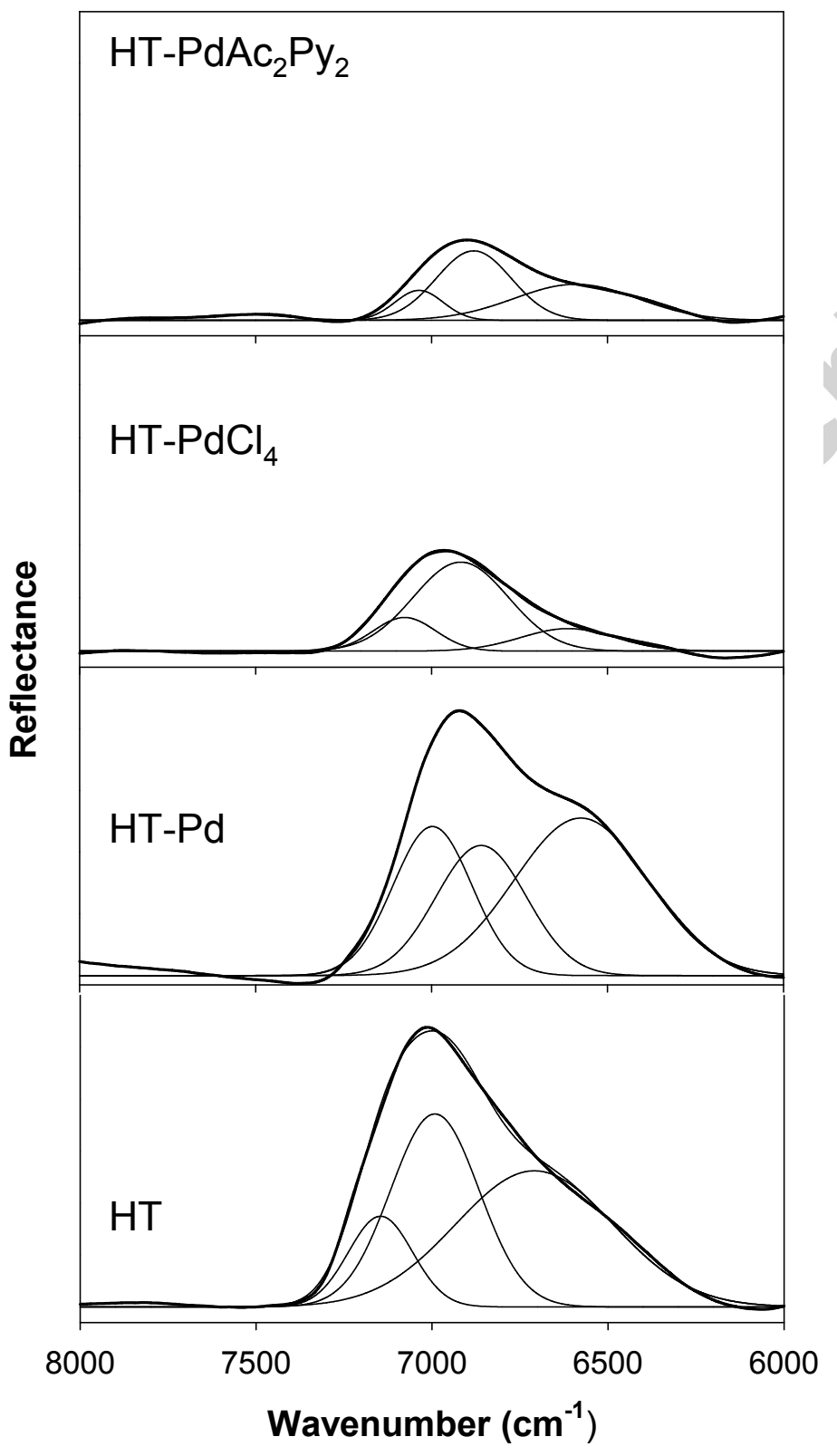


Figure 7. NIR spectra of synthesized catalysts in the $5500-4000 \mathrm{~cm}^{-1}$ region.

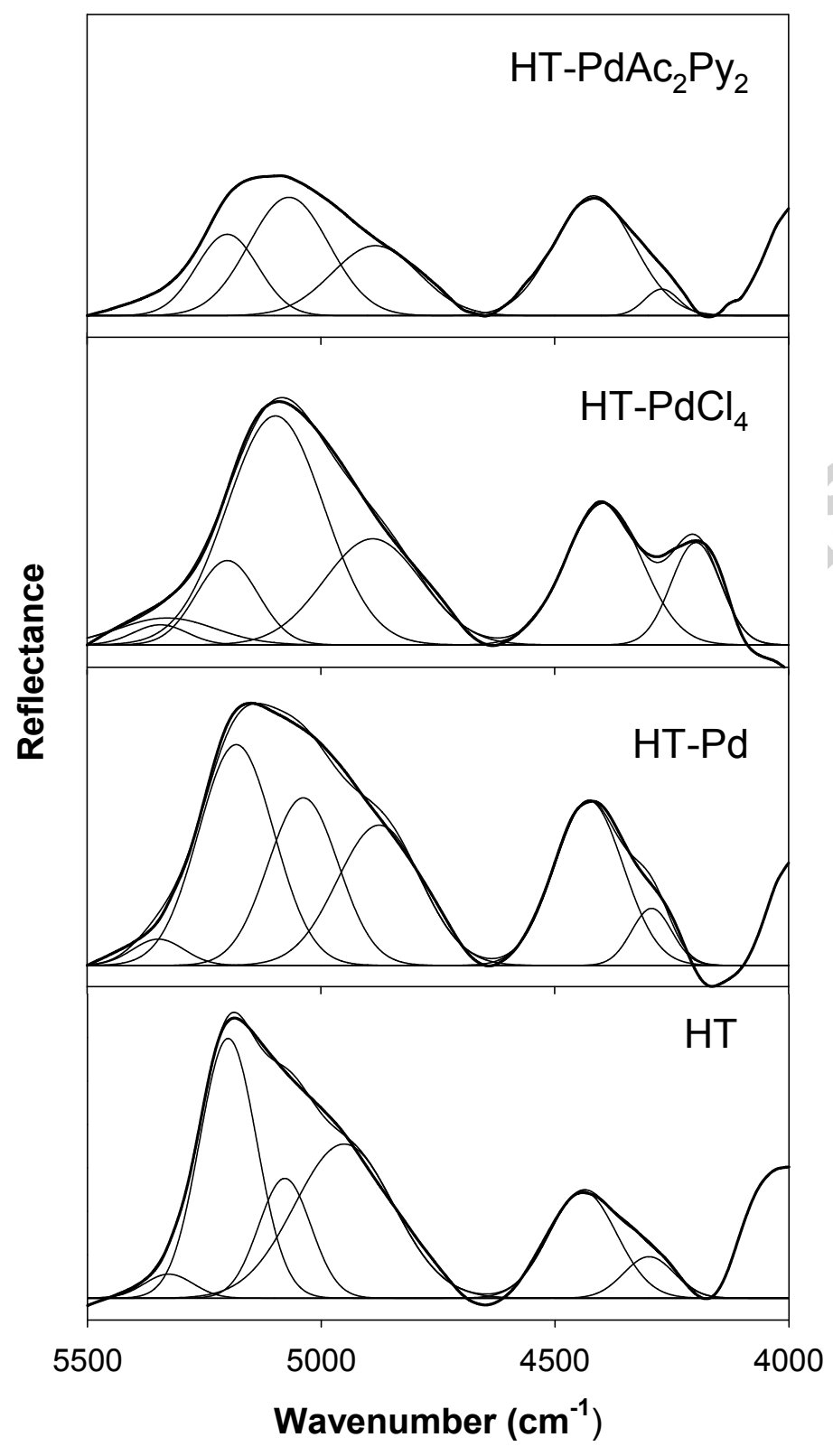




\section{RESEARCH HIGHLIGHTS}

- We use for the first time the NIR spectroscopy to characterize palladium supported over hydrotalcites catalysts. The catalysts exhibited three distinct zones with marked differences in fundamental stretching vibrations of $\mathrm{OH}$ groups. The NIR region allowed the pure $\mathrm{LDH}$ to be discriminated from the Pd-containing catalysts on the basis of the presence of electronic bands due to the metal. 